\title{
TRADITSIOON JA AVANGARD KIRJANDUSES
}

\author{
Luule Epner, Ave Mattheus, Piret Viires
}

Mõistepaari traditsioon - avangard on kultuuri arenguprotsesside käsiteludes laialt kasutatud; nende keerukate omavaheliste suhete ja vastastikmõjude kaudu on võimalik kunstide arengudünaamikat teljestada ja analüüsile allutada. ${ }^{1}$ Hiljemalt renessansist alates on traditsiooni ja uuenduse suhted olnud kultuurikriitiliste vaidluste teemaks, kuna tegemist ei ole mitte neutraalselt kirjeldavate, vaid ideoloogiliselt laetud mõistetega, mille abil väärtustatakse kunstinähtusi. Arvukaid selleteemalisi uurimusi vaadeldes torkab aga silma teatav asümmeetria - avangardist kirjutatakse sootuks rohkem kui traditsioonist. Traditsioon tundub sageli olevat nimetatud mõistepaari justkui iseendast mõistetav osapool, mille najal tegeldakse põhiliselt ikka avangardi problemaatikaga. Ka eesti kirjandusteaduse vallast on nimetada ennekõike Tiit Hennoste mahukas monograafia „Eesti kirjanduslik avangard 20. sajandi algul. Hüpped modernismi poole I“ (2016). Niisiis on asjakohane küsida, mida mõistetakse kirjandusliku traditsiooni all.

Sõna traditsioon pärineb ladina keelest: trāditio tähendab ülevõi edasiandmist, osutades seega protsesside jätkuvusele, pidevusele. Esinduslikus Metzleri kirjandus- ja kultuuriteooria leksikonis (Metzler 2001: 641) defineeritakse traditsiooni väljakujunenu, pärimusliku, harjumuslikuks saanu kaudu ning osutatakse sellele, et traditsioonist räägitakse enamasti vastandmõistete, nagu (traditsiooni) uuendus, katkestus, murrang abil. Traditsioon on midagi vana, püsivat ja stabiilset, mis seatakse vastu millelegi uudsele, moodsale ja lühiajalisele. Traditsioon sünnib matkimise, kordamise ja kinnistamise tulemusel ning vastandub tavapärasest (normist)

\footnotetext{
Värskendava vaheldusena käsitleti paarkümmend aastat tagasi kirjandusajaloo küsimusi seminarides ja artiklikogumikus pealkirjaga „Traditsioon ja pluralism“ (Tartu: Eesti Kirjandusmuuseum, 1998).
} 
kõrvale kaldumisele, individuaalsele ja isepärasele. Sellisena, nagu tõdeb ka T. S. Eliot oma krestomaatilises essees „Traditsioon ja individuaalne talent" (1919), esineb mõiste "traditsiooniline“ enamasti laitvas tähenduses (Eliot 1997: 9). Kuid Eliot arutleb edasi, et tihti hindame autorite juures kõrgelt just nende sängitatust traditsiooni, ajalootaju, suhet surnud eelkäijatega, ja jõuab siis traditsiooni kui suure elava terviku ehk pidevalt uueneva ja areneva nähtuse mõtestamiseni, mida on suutelised kujundama vaid tõeliselt individuaalsed talendid. Eliot visandab siin muutuse, mis iseloomustab traditsioonist mõtlemist 20. sajandist alates.

Traditsioonis väljendub kultuuri järjepidevus ning see kannab kultuurimälu, sidudes olevikku mineviku väärtustega - mispuhul räägitakse tihti pärandist, mida tuleb hoida ja edasi kanda. Taolises tähenduses ei kuulu traditsiooni mitte kõik, mis mineviku kultuuris ja kirjanduses on loodud, vaid selle üldiselt hinnatud osa. Kui traditsioon samastatakse säilitamisväärse, mõõtu andva või püsiväärtuslikuga, siis tekib küsimus sellise valiku alustest ning traditsioon seotakse kaanoni ja klassika kontseptsioonidega. Selliselt mõistetud traditsioon on olemuselt normatiivne, nn suurte tekstide kogum.

Kaanoni (kr kanōn eeskiri, määrus, reegel) mõiste tuli kirjandusse ristiusu kiriku kaudu, kus see tähistas eeskirja, tava või pühaks tunnistatud tekstide kogumit, mille järgimine on kohustuslik. Kirjanduses hakati kaanonist kui mingi inimrühma poolt väärtuslikuks ja säilitamisväärseks peetavast tekstikogust või tekstide tõlgendamise viisist (kanooniline interpretatsioon) rääkima alates 18. sajandi lõpust. Ja kuigi kirjanduskaanon on mitteametlik ja implitsiitne (s.t mitte eksplitsiitselt kirja pandud), mitte-objektiivne ja kohati isegi väga subjektiivne, sest põhineb mõjukate lugejate (nt kirjanike, kriitikute, teadlaste) ja kultuuriinstitutsioonide (ülikoolid, erialaorganisatsioonid) otsustel (vt Hennoste 1997), omab see suurt tähtsust kollektiivi sidustamisel. Kaanon loob ja kinnistab kollektiivset identiteeti, pakub rühmale olulisi väärtusi ja norme, käitumisjuhiseid ja -reegleid ning võimaldab suhtlust teatud kindlatel teemadel (Metzler 2001: 363). Klassika (ld classicus 
'varade hindamisel kõrgeimasse maksuklassi kuuluv, silmapaistev') all mõistetakse eeskujulikku, esmaklassilist, kõrgetasemelist, jääva tähtsusega kultuurisaavutust, ka ühe rahva kultuurilist kõrgsaavutust või õitsenguaega teatud ajaperioodil.

Ent uurimused on näidanud, et ei kaanon ega traditsioon pole midagi stabiilset ja muutumatut, vaid ajalooliselt ja kultuuriliselt pidevalt teisenev keeruliste valikute ja tõlgenduste protsess, milles mängivad rolli nii kanoniseeritu sisemised kui ka välised faktorid. Ehk nagu Tiit Hennoste on kirjanduskaanoni kohta öelnud: see on tunduvalt laiem nähtus kui kirjandus, „[s]ee on poliitiline, ideoloogiline, pedagoogiline, majanduslik nähtus“ (Hennoste 1997: 63). Nii nagu tänapäeval esineb kõrvuti erinevaid (kirjandus)kaanoneid, olemasolevat kaanonit laiendatakse, mitmekesistatakse või lõhutakse, on muutunud ka arusaam traditsioonist. Seda ei peeta enam millekski pärimuslikuks, igivanaks või stabiilseks, mida ikka ja jälle taasavastatakse ja justkui muutumatuna edasi kantakse, vaid millekski konstrueerituks ja leiutatuks, mida pidevalt taasluuakse ja millega aktiivselt suhestutakse, vastavalt selle ajaperioodi vajadustele ja võimalustele, kus ise asutakse.

Esmakordselt juhtisid traditsioonile kui sotsiaalsele konstruktsioonile tähelepanu Eric Hobsbawm ja Terence Ranger oma mõjuvõimsas kogumikus „The Invention of Tradition“ (1983, „Traditsiooni leiutamine"). Hobsbawmi järgi on leiutatud traditsioon kimp rituaalseid või sümboolseid praktikaid, mida kujundavad avalikult või vaikimisi heaks kiidetud reeglid eesmärgiga kinnistada läbi kordamise teatud väärtusi või käitumistavasid ja luua seeläbi katkematu side möödanikuga; viidates muutumatule minevikule, luuakse kiirelt muutuvas olevikus mingi toetuspind, kindel struktuur, ajalooline järjepidevus, millest saab kinni hoida (Hobsbawm 2000: 1-2). Traditsioonide leiutamine toimub eriti intensiivselt ajal, mil kiired ühiskondlikud muutused nõrgendavad või lõhuvad sotsiaalseid mustreid, mida olid omakorda toetanud vanad traditsioonid.

Ükskõik millist arusaama traditsioonist ka ei eelistata, on selge, et traditsioonita ei oleks kultuurilist ega kirjanduslikku arengut 
ja uuenemist. Tekstid sünnivad tänu tsitaatidele või viidetele oma kirjanduslikele eelkäijatele, iga uus nähtus vajab traditsiooni kasvõi pinna mõttes, millelt tõukuda, et uudsus oleks üldse tajutav. Viise, kuidas traditsiooniga suhestutakse, on erinevaid, alates olemasoleva traditsiooni raames töötamisest, oma eelkäijatega (intertekstuaalset ja/või intermeedialist) dialoogi pidades, nende mõtteid hoides, säilitades ja edasi kandes (adaptatsioonid, tõlked) kuni traditsiooni eituse ja lõhkumiseni välja. Seejuures võib suhestumine eelkäijatega aset leida kõikidel kirjanduse tasanditel, alustades ideedest ja teemadest, kujutamistehnikatest ja kunstivõtetest ning lõpetades stiilide ja žanrimudelitega.

Üks viljakamaid ja omanäolisemaid traditsiooni vastu astunud kirjanduslikke nähtusi on avangardism. Mõiste avangard on märksa hilisem kui traditsioon, nagu näitab ka etümoloogia: prantsuse avant-garde 'eelvägi' tuli kirjanduse ja kunstiga seoses käibele 19. sajandi alguskümnendeil; selle sõna militaarsed konnotatsioonid pole sugugi tähtsusetud - avangardism on sageli tähendanud aktiivset vastuseisu traditsioonile, võitlust vanade vormidega. Ajalises plaanis on avangardistid need loojad, kes on n-ö oma ajast ees („eelvägi”) ning panevad alguse millelegi uuele kirjanduses. Richard Kostelanetz (1982: 3) toob välja kolm avangardistliku kunstiteose kriteeriumit: see ületab mingis olulises suhtes kehtivaid kunstikonventsioone, distantseerudes selgesti käibivatest kunstipraktikatest; seetõttu võtab aega, kuni teos leiab laiema publiku; tavaliselt inspireerib teos samalaadseid katsetusi tulevikus. Mõistagi on avangardistlikud katsetused alguses vähemuses, kuid nagu osutatud, võib neist areneda kindlapõhjaline ja populaarne traditsioon, millele uued põlvkonnad omakorda vastanduvad.

Kirjandusajaloos märgib mõiste avangard eeskätt uuendusi 19.20. sajandil, mis leidsid aset modernismi raamistikus; keerulisem on postmodernismi suhe avangardi diskursusega. Avangardina on käsitletud kõigepealt 20. sajandi alguse uuenduslikke kirjandusvoole (üldistatult nimetatakse neid ka ajalooliseks avangardiks), nagu futurism, dadaism, ekspressionism, sürrealism, mis moodustavad 
modernismi kõige radikaalsema, tõepoolest eelväena toiminud osa. Tiit Hennoste peab avangardismi tuumaks uuendajaid, kes tegutsevad tavaliselt koos, rühmituse või liikumisena, ning kel on manifesti kujul esitatud programm. Radikaalsed, traditsiooni eitavad eksperimendid kirjanduses seostuvad radikaalse ideoloogiaga. (Hennoste 2016: 175-176) Teine uuendusliikumiste laine, mida mõnikord koondatakse neoavangardi nimetuse alla, tõusis 1960.-1970. aastatel. Mõlemal puhul varieerub suurel määral avangardistide suhe traditsiooniga: täieliku katkestuse taotlemine pole ainus strateegia, traditsiooni ka nihestatakse, töötatakse ümber, konstrueeritakse alternatiivne kaanon, mis sobib uue esteetikaga vms (vt Bürger 2010: 704).

Peter Bürgeri mõjukas monograafia "Theorie der Avantgarde” (1974, „Avangarditeooria“) tõstis esile avangardistlike liikumiste suhte kunsti-institutsioonidega. Selle suhte paradoksid tulevad eriti aredalt ilmsiks visuaalkunsti ajaloos, samuti näiteks teatrikunstis, kuid ka avangardsete kirjandusvoolude ajaloos võib leida katseid küsimustada ja muuta olemasolevat institutsioonilist raamistikku ning ümber mõtestada kirjanduse funktsioone, kirjaniku positsiooni ühiskonnas jms. Kunstiliste uuendustega liituvad sel juhul kirjanduspoliitilised eesmärgid ning neid ühendab eitav hoiak ühiskonnas traditsiooniliste, tavapäraseks muutunud praktikate suhtes. Kuid uuenduslike vormide ja praktikate levik, avangardi etableerumine ja kanoniseerimine muudab need traditsiooni osaks - mis muidugi teiseneb ja muutub seeläbi ka ise.

Eelnevast on näha, et traditsiooni ja avangardi suhted on mitmetahuline ja lai teema, mis hõlmab mitmeid valdkondi. Käesoleva Philologia Estonica Tallinnensise teemanumber „Traditsioon ja avangard“ pakubki nii eesti kui ka muude kirjanduste näitel seitset vaadet traditsiooni ja avangardi mitmekesisele pingesuhtele.

Kogumiku avab kirjandusuurija Rebekka Lotmani artikkel „Traditsioonist ja modernismist eesti sonetis“. Artiklis vaadeldakse modernismi ja traditsiooni kohtumist eestikeelses sonetis ja arutletakse 20. sajandi alguse eesti modernistide kahetise ülesande 
üle - luues ühtaegu sonetitraditsiooni, uuendasid nad samas eesti luulekeelt. Artiklis soovitatakse lähtuda traditsiooni ja modernismi käsitlemisel historistlikust lähenemisviisist ja ühtlasi demonstreeritakse, et eesti soneti puhul on arhaism ja novaatorlus käinud käsikäes.

Kirjandusuurija ja koolikirjanduse óppematerjalide koostaja Katre Talviste käsitleb oma artiklis „Traditsioon ja avangard eesti kirjandusõpetuse kujunemisloos" kaht traditsiooni, mis kujunesid välja 20. sajandi eesti üldhariduskooli vanema astme kirjandusõpetuses. Üks neist käsitleb kirjandust kaherajalise mudelina, kus eesti kirjanduse kõrval õpetatakse paralleelselt teiste rahvaste kirjandusi, teises, mis keskendub õppesisu, õpitegevuste ja -väljundite laadile, domineerivad ajaloolis-eluloolised käsitlused kirjanduse kohta. Talviste arutleb oma artiklis 21. sajandi õppekavaarenduses esile kerkinud nõuete üle neid traditsioone muuta ja tasakaalustada.

Kirjandusuurija Piret Viires uurib oma artiklis „Traditsioon ja avangard: lisandusi 1990. aastate kirjandusmuutustele“ kolme 1990. aastal ilmunud märgilise teose - Mati Undi „Öös on asju“, Peeter Sauteri „Indigo“ ja Jaan Unduski „Kuum“ - rolli proosauuenduses. Artiklis arutletakse, kas ja kuidas need 1990. aastal ilmunud avangardsed proosateosed muutusid järgnevatel kümnenditel eesti kirjandustraditsiooni osaks, ja pakutakse omapoolne vaade eesti kirjanduskaanoni kujunemisele 1990. ja 2000. aastatel, kus oluline roll on olnud nii sünkroonkriitikal, kirjanduslugudel kui ka riiklikul õppekaval ja kooliõpikutel.

Teatriuurijate Anneli Saro ja Hedi-Liis Toome artikkel „Kunstiliste maailmade kehastamine Karl Ristikivi „Hingede öö“ näitel“ küsib, kuidas klassikat tajutakse, tõlgendatakse ja teatrikeelde üle kantakse. Autorid võtavad vaatluse alla Ristikivi eesti kirjanduskaanonisse kuuluva romaani, sellest lähtuva Labürintteatriühenduse G9 rännaklavastuse (2018) Tartu Ülikooli Ajaloomuuseumis, kus kasutati osavõtuteatri vormi, ja lavastuse vaatajate - õieti selles osalejate - vastuvõtukogemuse. Lavastuse retseptsioonimustrite selgitamiseks intervjueeriti paarikümmend vaatajat ning intervjuud tehti ka lavastuse loojatega. Lugemist, lavastamist (ülekannet 
materiaalsesse keskkonda) ja etenduse vastuvõttu seob omavahel kehastamiskogemus, millele artikkel ongi keskendatud. Mitmekülgse materjali alusel uuritakse kehastamist kui taju-, tõlgendusja kaasloomeprotsessi nii vastuvõtjate (lugejate, vaatajate) kui ka lavastuse loojate vaatepunktist.

Paavo Põldmäe vaatleb artiklis „Ajalooline müüt Jaan Kaplinski draamas „Neljakuningapäev““‘ Jüriöö ülestõusu ja nelja eestlaste kuninga tapmise kujutamist Kaplinski 1970. aastate algul valminud näidendis ning näidendi kaht lavatõlgendust: Mikk Mikiveri lavastust 1977. aastal ja Rudolf Allaberdi 1987. aastal esietendunud tõlgendust. Kaplinski draama, mis on osa nn Jüriöö-tekstist, Eesti rahvusliku ajalookultuuri tüvitekstist (Marek Tamm), seostub 1960.-1970. aastate teatri- ja draamauuenduse aegu esile tõusnud allegoorilise, mõistukõnelise kujutamislaadiga. Artiklis uuritakse, milline oli „Neljakuningapäeva“ ning selle üpris erinevas ühiskondlikus taustsüsteemis valminud lavastuste tähendus ja vastuvõtt.

Kaks artiklit käsitlevad traditsiooni ja avangardi suhet maailmakirjanduses või laiemas kultuurielus. Hispaania kultuuri uurija Merilin Kotta analüüsib oma artiklis „García Márqueze „Patriarhi sügis" traditsiooni ja uuenduse vahel" ühe tuntuma maailmakirjanduse romaani keskset kunstilist kujundit, kordust teose struktuuri ja loo tasandil. Tuues näiteid sõna- ja motiivikordustest, näitab Kotta, kuidas üldiselt traditsiooni kinnistava võttena tuntud kordus võib uude konteksti paigutatuna mõjuda hoopis uuenduslikkust tähistava kujundina, sest küsimärgistab muutumatust ja ainutõde.

Teemanumbri lõpetab saksa kirjanduse ja kultuuri uurija Aigi Heero ingliskeelne artikkel „On cultural contacts and their impact on literature in Tallinn in the early $17^{\text {th }}$ century“ („Kultuurikontaktidest ja nende mõjust Tallinna kirjandusväljale 17. sajandi alguses“). Artikkel käsitleb kultuurimuudatusi Tallinna ja Põhja-Eesti kultuuriväljal varasel uusajal, täpsemalt 1630. aastate esimesel poolel, mis oli murranguline aeg piirkonna kultuurielus. Artiklis näidatakse, kuidas sel perioodil saabus Tallinna hulgaliselt sisserändajaid peamiselt Põhja-Saksamaalt, kellega koos saabusid ka uued, värsked 
kultuurilised ideed. Artiklis arutletakse, kuidas need uuenduslikud ideed ja kultuurinähtused mõjutasid kohaliku kultuuri arengut ning kujundasid seeläbi ka eesti kultuuritraditsiooni.

Nii hõlmab Philologia Estonica Tallinnensise number traditsiooni ja avangardi temaatika väga erinevaid aspekte. Üks on aga kõigile neile artiklitele suures osas ühine - vaadeldakse, kuidas uued nähtused, vormivõtted või teemad on saanud või ei ole saanud kas eesti või mõne muu rahvuskultuuri traditsiooni osaks ja kuidas traditsioon seeläbi on muutunud.

Elame praegu kiirete ühiskondlik-kultuuriliste muutuste ajal, mil huvi traditsiooni ja avangardi tähenduste ning kultuuri arengudünaamika vastu on tõusnud taas päevakorda. Loodame, et siinne Philologia Estonica Tallinnensise teemanumber annab oma panuse traditsiooni ja avangardi suhete mõtestamisse ja saab peatselt lisa uute käsitluste näol.

\section{KIRJANDUS}

Bürger, Peter 2010. Avant-Garde and Neo-Avant-Garde: An Attempt to

Answer Certain Critics of „Theory of the Avant-Garde”. - New Literary History 41: 4, 695-715.

Eliot, Thomas Stearns 1997. Traditsioon ja individuaalne talent. - T. S. Eliot, Valitud esseesid. Koost ja tlk Jaak Rähesoo. Tallinn: Hortus Litterarum, 9-21.

Hennoste, Tiit 1997. Kaanon. Kaanan. - Vikerkaar 12, 59-70.

Hennoste, Tiit 2016. Eesti kirjanduslik avangard 20. sajandi algul. Hüpped modernismi poole I. Tallinn - Tartu: Tartu ülikooli kirjastus.

Hobsbawm, Erik 2000. Introduction. Inventing Traditions. - The Invention of Tradition. Eds. Eric Hobsbawm, Terence Ranger. Cambridge: Cambridge University Press, 1-14.

Kostelanetz, Richard 1982. Introduction: What is Avant-Garde? - The Avant-Garde Tradition in Literature. Ed. Richard Kostelanetz. Buffalo, New York: Prometheus Books, 3-6.

Metzler 2001 = Metzler Lexikon Literatur- und Kulturtheorie: Ansätze, Personen, Grundbegriffe. 2. Auflage. Hrsg. Ansgar Nünning. Stuttgart, Weimar: Metzler. 